\title{
Application of amplicon-based targeted sequencing with the molecular barcoding system to detect uncommon minor EGFR mutations in patients with treatment-naïve lung adenocarcinoma
}

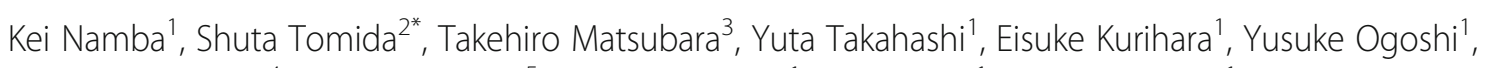
Takahiro Yoshioka ${ }^{4}$, Tatsuaki Takeda ${ }^{5}$, Hidejiro Torigoe ${ }^{1}$, Hiroki Sato ${ }^{1}$, Kazuhiko Shien ${ }^{1}$, Hiromasa Yamamoto ${ }^{1}$, Junichi Soh', Kazunori Tsukuda' and Shinichi Toyooka'

\begin{abstract}
Background: In lung cancer, epidermal growth factor receptor (EGFR) tyrosine kinase inhibitor sensitizing mutations co-existing with rare minor EGFR mutations are known as compound mutations. These minor EGFR mutations can lead to acquired resistance after EGFR tyrosine kinase inhibitor treatment, so determining the mutation status of patients is important. However, using amplicon-based targeted deep sequencing based on next-generation sequencing to characterize mutations is prone to sequencing error. We therefore assessed the benefit of incorporating molecular barcoding with high-throughput sequencing to investigate genomic heterogeneity in treatment-naïve patients who have undergone resection of their non-small cell lung cancer (NSCLC) EGFR mutations.

Methods: We performed amplicon-based targeted sequencing with the molecular barcoding system (MBS) to detect major common EGFR mutations and uncommon minor mutations at a $0.5 \%$ allele frequency in fresh-frozen lung cancer samples.
\end{abstract}

Results: Profiles of the common mutations of EGFR identified by MBS corresponded with the results of clinical testing in 63 (98.4\%) out of 64 cases. Uncommon mutations of EGFR were detected in seven cases (10.9\%). Among the three types of major EGFR mutations, patients with the G719X mutation had a significantly higher incidence of compound mutations than those with the L858R mutation or exon 19 deletion $(p=0.0052)$. This was validated in an independent cohort from the Cancer Genome Atlas dataset ( $p=0.018)$.

Conclusions: Our findings demonstrate the feasibility of using the MBS to establish an accurate NSCLC patient genotype. This work will help understand the molecular basis of EGFR compound mutations in NSCLC, and could aid the development of new treatment modalities.

Keywords: Non-small cell lung cancer, Epidermal growth factor receptor, Compound mutations, Molecular barcoding, Genomic heterogeneity, Patient genotype, Next-generation sequencing, Molecular barcoding, EGFR, Non-small cell lung cancer, Treatment-naïve, Sequence artifact, Clinical sequencing, Uncommon mutation, Mutation detection

\footnotetext{
* Correspondence: shuta.tomida@okayama-u.ac.jp

${ }^{2}$ Department of Biobank, Okayama University Graduate School of Medicine,

Dentistry and Pharmaceutical Sciences, 2-5-1 Shikata-cho, Kita-ku, Okayama

City 700-8558, Japan

Full list of author information is available at the end of the article
}

(c) The Author(s). 2019 Open Access This article is distributed under the terms of the Creative Commons Attribution 4.0 International License (http://creativecommons.org/licenses/by/4.0/), which permits unrestricted use, distribution, and reproduction in any medium, provided you give appropriate credit to the original author(s) and the source, provide a link to the Creative Commons license, and indicate if changes were made. The Creative Commons Public Domain Dedication waiver (http://creativecommons.org/publicdomain/zero/1.0/) applies to the data made available in this article, unless otherwise stated. 


\section{Background}

Lung cancer is the leading cause of cancer mortality worldwide, and non-small cell lung cancer (NSCLC) accounts for more than $85 \%$ of all lung cancers $[1,2]$. The molecular profiles of NSCLC have been extensively analyzed, and revealed that activating mutations in the epidermal growth factor receptor gene (EGFR) are found in approximately $10-15 \%$ of Caucasian patients and $30-$ $40 \%$ of Asian patients with lung adenocarcinoma [3-8]. The successful development of molecular targeting agents that inhibit growth signals from driver mutations has improved the treatment outcome of adenocarcinoma patients with EGFR mutations [9-11].

Recently, several reports have demonstrated the existence of compound EGFR mutations, where an EGFR tyrosine kinase inhibitor (EGFR-TKI) sensitizing mutation coexists with uncommon mutations such as T790 $\mathrm{M}, \mathrm{E} 709 \mathrm{G} / \mathrm{K}, \mathrm{R} 776 \mathrm{H}$, and $\mathrm{L} 844 \mathrm{~V}$ [12-15]. These rare minor mutations cause acquired resistance after EGFRTKI treatment [14, 15], leading to disease progression. Thus, it is important to understand the status of uncommon as well as common mutations.

The clinical implementation of amplicon-based targeted deep sequencing based on next-generation sequencing (NGS) technologies has been widely adopted [16], and enables the analysis of small amounts of input DNA such as those extracted from formalin-fixed paraffin-embedded samples. However, a major problem of high-throughput DNA sequencing is the increased rate of errors introduced during sample preparation and sequencing, resulting in difficulties in determining the true genotype status, especially for infrequent mutant allele $[17,18]$. The molecular barcoding system (MBS) aims to resolve the impact of enrichment and sequencing artifacts, and has the potential to improve the mutation detection accuracy [18-20], enabling us to understand genomic heterogeneity in NSCLC.

In the current study, we used a high-sensitivity, amplicon-based targeted deep sequencing method that incorporates the MBS to investigate genomic heterogeneity in treatment-naïve NSCLC patients with EGFR mutations who have undergone resection of their cancers.

\section{Methods}

\section{Tumor preparation and DNA extraction}

We retrospectively analyzed 590 consecutive patients who underwent surgical resection for primary lung cancer at Okayama University Hospital between January 2012 and December 2015. The inclusion criteria were as follows: (1) treatment-naïve before surgery, (2) histologic documentation of adenocarcinoma, and (3) a positive EGFR mutation status tested using a standard conventional method (peptide nucleic acid-locked nucleic acid PCR clamp method, or clinical testing) [21]. In the PCR clamp method, it is possible to detect the following EGFR mutations; Exon 19 deletions, L858R, L861Q, T790 M and G719A/S/C. Patients without surgical pathology reports or stored fresh-frozen samples were excluded.

Out of the remaining 531 treatment-naïve patients, 415 (78\%) were diagnosed with adenocarcinoma (206 men and 209 women). Based on clinical tests, 169 patients (59 [35\%] men and 110 women) were shown to be EGFR mutation-positive (Additional file 1: Figure S1). Sixty-four of these 169 EGFR mutation-positive adenocarcinomas were randomly selected and sequenced with the MBS.

Frozen lung cancer samples were procured at the time of surgery, immediately frozen in liquid nitrogen, and stored until use. Genomic DNA from available fresh-frozen tissue samples was extracted using the phenol-chloroform method. The DNA quality and concentrations were assessed using the Qubit 3.0 Fluorometer (Thermo Fisher Scientific, Waltham, MA, USA).

\section{Library preparation using the MBS}

Target enrichment was performed on $100 \mathrm{ng}$ of input DNA using the HaloPlex ${ }^{\mathrm{HS}}$ system (Agilent Technologies, Santa Clara, CA), which is a high-sensitivity, amplicon-based targeted sequencing method incorporating the MBS in the DNA library. Library was prepared based on the manufacturer's protocol for ClearSeq Cancer HS, ILM, which was designed to identify somatic variants in 47 cancer-related genes (Additional file 2: Table S1) targeting known COSMIC hotspots found to be associated with a broad range of cancer types as well as published drug targets (https://www.agilent.com/en/product/amplicon-based-nextgeneration-sequencing-(ngs)/amplicon-target-capture-kits/ haloplexhs-custom-kits-232856). Sequencing was performed using the MiSeq (v3 600-cycle kit (Illumina, San Diego, CA, USA) according to the manufacturer's recommendations for paired-end sequencing $(2 \times 300$ cycles $)$ and the HiSeq 2500 Rapid mode 300-cycle (Illumina). Patient data were collected retrospectively from clinical records.

The generated sequences were processed in-house using Agilent SureCall software, which is used exclusively with the HaloPlex ${ }^{\mathrm{HS}}$ system. Briefly, the molecular barcode analysis consisted of the following steps: first, the individual DNA molecules were tagged with molecular barcodes during library preparation. Next reads were aligned to the same genomic coordinates. Then, the reads with an identical molecular barcode were grouped into each molecular family. Finally, the base sequences for a molecular barcode were consolidated to one read per molecular barcode (random error, including PCR errors and sequence errors, were removed) (Fig. 1a). 


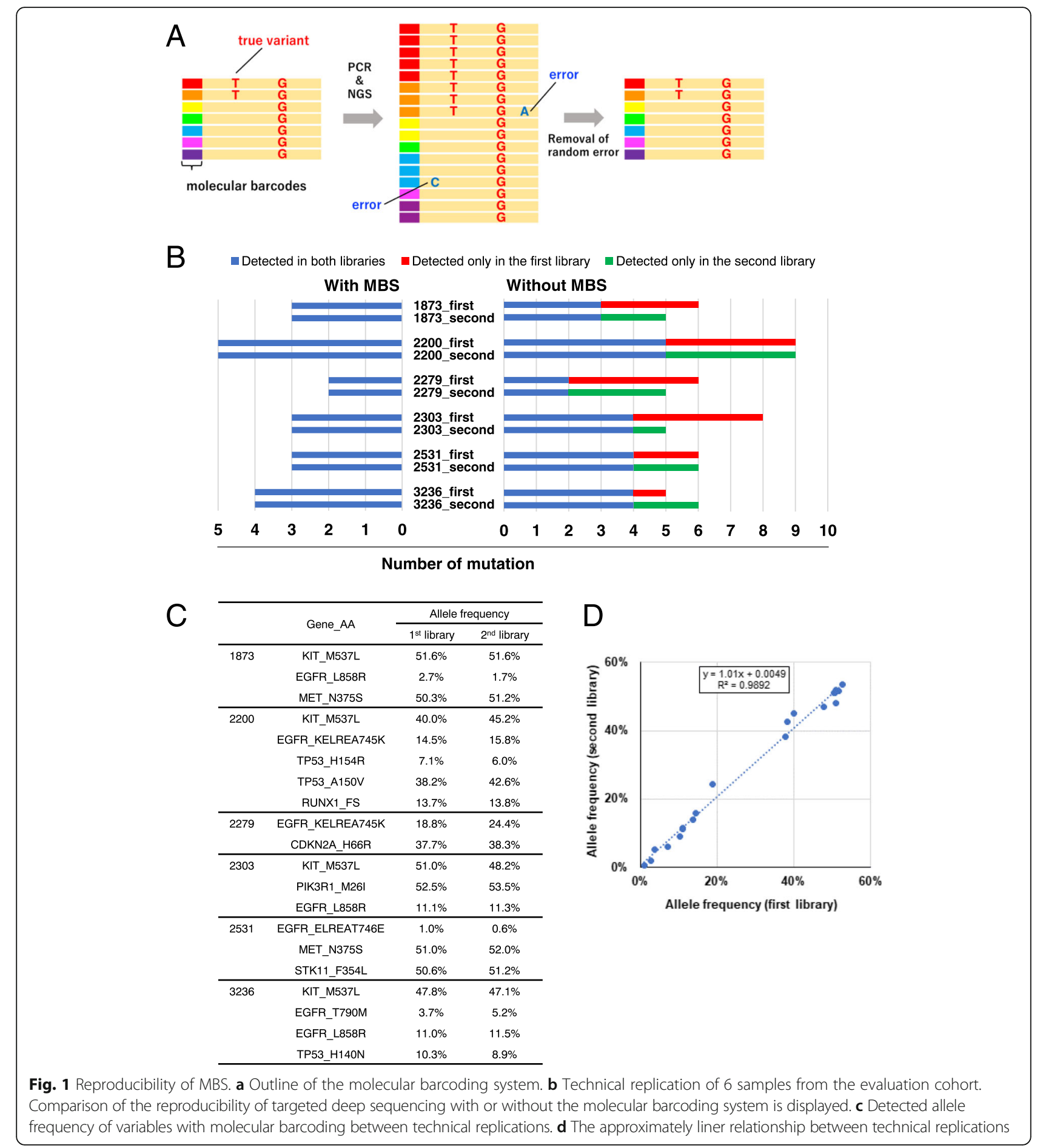

\section{Direct sequencing}

Rare EGFR mutations were confirmed using standard DNA sequencing techniques with the direct sequencing of several EGFR exons. Briefly, DNA was isolated from the sample, quantified, and subjected to PCR using primers for exons 15 to 21 of EGFR (Additional file 3:
Table S2). The PCR products were then analyzed using bidirectional direct DNA sequencing.

\section{Analysis of The Cancer Genome Atlas (TCGA) datasets}

TCGA datasets were analyzed and downloaded via the cBioPortal (http://www.cbioportal.org). RNA-Seq gene 
expression data for TCGA samples were collected from the Genomic Data Commons Data Portal (https://portal.gdc.cancer.gov). Microarray gene expression data for 127 lung adenocarcinomas with EGFR mutations from the Japanese National Cancer Center Research Institute were collected from Gene Expression Omnibus (https:// www.ncbi.nlm.nih.gov/geo/) as GSE31210. Functional analyses of the TCGA samples were performed using gene set enrichment analysis (GSEA) (Molecular Signatures Database v5.0) [22].

\section{Statistical analysis}

Statistical analyses were performed using GraphPad Prism 7 (GraphPad Software). Overall survival (OS) rates and recurrence-free survival (RFS) rates were calculated using the Kaplan-Meier method, and differences in survival rates between the groups were compared using the log-rank test. A value of $p<0.05$ was considered statistically significant.

\section{Results}

\section{Reproducibility of MBSs}

To confirm the reproducibility of targeted deep sequencing with or without MBSs, we examined the technical reproducibility using six samples (Additional file 4: Table S3). The first and the second libraries were prepared independently from the same DNA extraction of each samples. Using MBS, the exact same results were obtained for the first and the second libraries of \#1873, such as three mutations for KIT, EGFR and MET (Fig. 1b, c). Without MBS, however, three orphan mutations were detected additionally for the first library as well as two orphan mutations for the second library of \#1873, resulting in the detection of six matched mutations plus five orphan mutations, corresponding to a reproducibility of 55\% (6/11) (Additional file 5: Table S4). In the same way, $100 \%$ reproducibility was obtained for all the six samples by using MBS, while on average $58 \%$ reproducibility was observed without MBS, ranging from 36\% (4/11) in patient \#2279 to 73\% (8/11) in patient \#3236 (Fig. 1b, Additional file 5: Table S4). Also, the allele frequencies of EGFR mutations detected with MBS were comparable between the two libraries across a wide range from around 1 to $50 \%$, including $0.6 \%$ of EGFR mutation for the second library of \#2351 (Fig. 1C), with significant correlation between the two libraries $\left(R^{2}=0.989\right.$, Fig. $\left.1 d\right)$, and thus demonstrating the reproducibility of MBS in quantifying allele frequency of EGFR mutations in lung cancer.

\section{Reducing potential sequence artifact using MBS}

Next, to evaluate the ability of MBS to reduce potential sequence artifacts, we performed targeted sequencing with or without MBS by expanding the samples to 28 (Additional file 4: Table S3). In order not to overestimate the ability of MBS to reduce potential sequence artifacts, systematic sequence artifacts, which were found in more than half of the sample, were filtered out before we compared the results. On average, 2.4 genetic alterations were detected with MBS (ranging from 1 to 4), while 3.3 genetic alterations were detected without MBS (ranging from 1 to 8) (Fig. 2a). One or more potential sequence artifacts (ranging from 1 to 7) were reduced in 17 of the 28 samples $(61 \%)$ with MBS. In addition, 11 out of 13 potential sequence artifacts were singletons, which were found in only one sample resulting in difficulty to distinguish those artifacts from the actual genetic alterations (Fig. 2b). Together, these results support the ability of MBS to reduce potential sequence artifacts.

\section{Determination of genomic heterogeneity}

To evaluate the concordance between EGFR mutations detected using clinical tests and targeted deep sequencing with MBS, DNA from 64 patients with adenocarcinoma was sequenced. The clinicopathological characteristics of the patients are summarized in Additional file 4: Table S3. All patients had histological confirmation of adenocarcinoma, and were classified as pathological stage IA $(n=39$, $61 \%)$, IB $(n=14,22 \%)$, and II-III $(n=11,17 \%)$ according to the TNM Classification of Malignant Tumors seventh edition. Examination of the status of common EGFR mutations identified via clinical tests revealed 42 (66\%) L858R mutations, 17 (27\%) exon 19 deletions, and five (8\%) G719S/A mutations. Targeted deep sequencing using MBS detected common EGFR mutations in 63 of the 64 patients (98.4\%) (Fig. 3a, Additional file 4: Table S3). Using MBS, we detected a T790M mutation with an allele frequency of $3.7 \%$ and an L858R mutation with an allele frequency of $11.0 \%$ in patient \#3236. In this patient, the T790 M mutation was not detected by routine clinical tests despite its inclusion in the examination. Instead, we confirmed the existence of $\mathrm{T} 790 \mathrm{M}$ in this patient using direct sequencing. From patient \#2233, we simultaneously acquired two samples (\#2233-1 and \#2233-2) from different lobes of the lung. The EGFR mutations detected from these tumors were $\mathrm{G} 719 \mathrm{~S}$ and $\mathrm{R} 776 \mathrm{H}$ mutations from one lesion (\#2233-1) and an exon 19 deletion from another (\#2233-2), indicating different tumor origins.

\section{Uncommon EGFR mutations}

Of 64 patients, uncommon EGFR mutations were detected in seven cases (10.9\%) (Fig. 3a, Table 1). The variant allele frequencies of uncommon EGFR mutations were $6.8-66 \%$. Four of the seven cases possessed an exon 18 E709G mutation together with an L858R mutation $(n=3)$ or a G719S mutation $(n=1)$. The other cases had an exon $20 \mathrm{R} 776 \mathrm{H}$ mutation with a G719S mutation $(\mathrm{n}=1)$, an exon 19 D761Y mutation with a G719S mutation $(\mathrm{n}=1)$, and an exon $15 \mathrm{G} 598 \mathrm{~V}$ mutation, a 

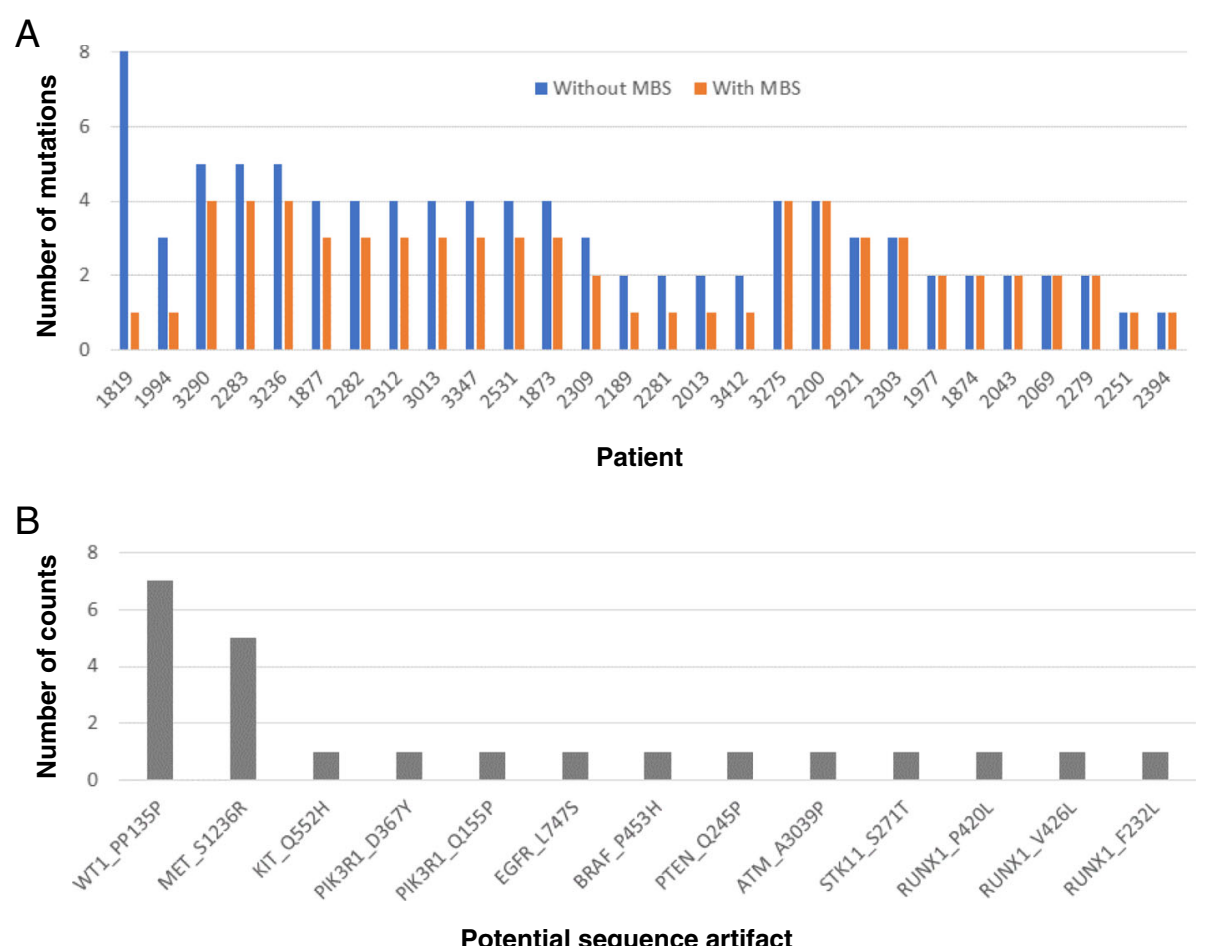

Fig. 2 Error suppression of MBS. a Detected genetic alterations with/without the use of molecular barcoding system $(n=28)$. b Potential sequence artifact found in samples sequenced without MBS

known pathogenic mutation localized to the extracellular domain [23], with an L858R mutation $(\mathrm{n}=1)$. These uncommon mutations were confirmed by direct sequencing (Additional file 6: Figure S2). The frequency of common mutation and uncommon mutation was almost identical in five cases which possessed E709G mutation or G598 V mutation. On the other hand, in the case of G719S/ $\mathrm{R} 776 \mathrm{H}$ and G719S/D761Y, the frequency of common mutation and uncommon mutation differed by more than $15 \%$ ( $31 \%$ vs $48,19 \%$ vs $66 \%$ ). We analyzed whether the differences of frequency differ by mutation, such as L858R vs. G719S, but, due to the small number of cases, statistically significant differences were not observed.

We further analyzed the potential correlations among the clinicopathological characteristics of patients with EGFR mutations. There were no differences in age, gender, or smoking habit distribution between the patients with a single mutation and those with a compound mutation, however, among patients with the three types of EGFR common mutations, those with G719X (60\%, 3/5) had a significantly higher incidence of concomitant uncommon EGFR mutations than those with L858R $(9.5 \%, 4 / 42)$ or exon 19 deletions $(0 \%, 0 / 17)(p=0.0052)$ (Table 2, Additional file 7: Table S5), as previously reported [24-26]. To validate these findings with an independent cohort, we analyzed the TCGA Pan-Lung cancer dataset, including 660 lung adenocarcinomas
(LUAD) [8]. In 104 LUAD patients, 123 EGFR mutations were detected. G719X, L858R, and exon 19 deletion mutations were found in five, 27, and 28 LUAD patients, respectively. Notably, patients with the G719X mutation had a significantly higher incidence of compound mutations $(60 \%, 3 / 5)$ compared with those with either L858R $(19 \%, 5 / 27)$ or the exon 19 deletion mutation $(7.1 \%, 2 /$ 28) ( $p=0.018$; Fig. 3b). These results strongly support our findings that patients with the G719X mutation are likely to have EGFR compound mutations.

To shed light on the molecular mechanisms, we compared gene expression profiles between patients with compound EGFR mutations and those with single EGFR mutations for respective mutations. A total of 44 RNA-Seq gene expression profiles were available from the TCGA LUAD dataset (L858R; $n=21$, exon 19 deletions; $n=20$, G719X; $n=3$ ). A total of 11 genes were significantly altered in patients with the G719X compound mutation, while only three were significantly repressed in patients with the L858R compound mutation, and six genes were altered in the patient with the exon 19 deletion compound mutation (Additional file 8: Figure S3A, B). In addition, we performed GSEA using hallmark gene sets, revealing that the following gene sets were positively correlated with the patient with the G719X compound mutation, such as "TGF beta signaling" and "UV response DN", while the following 


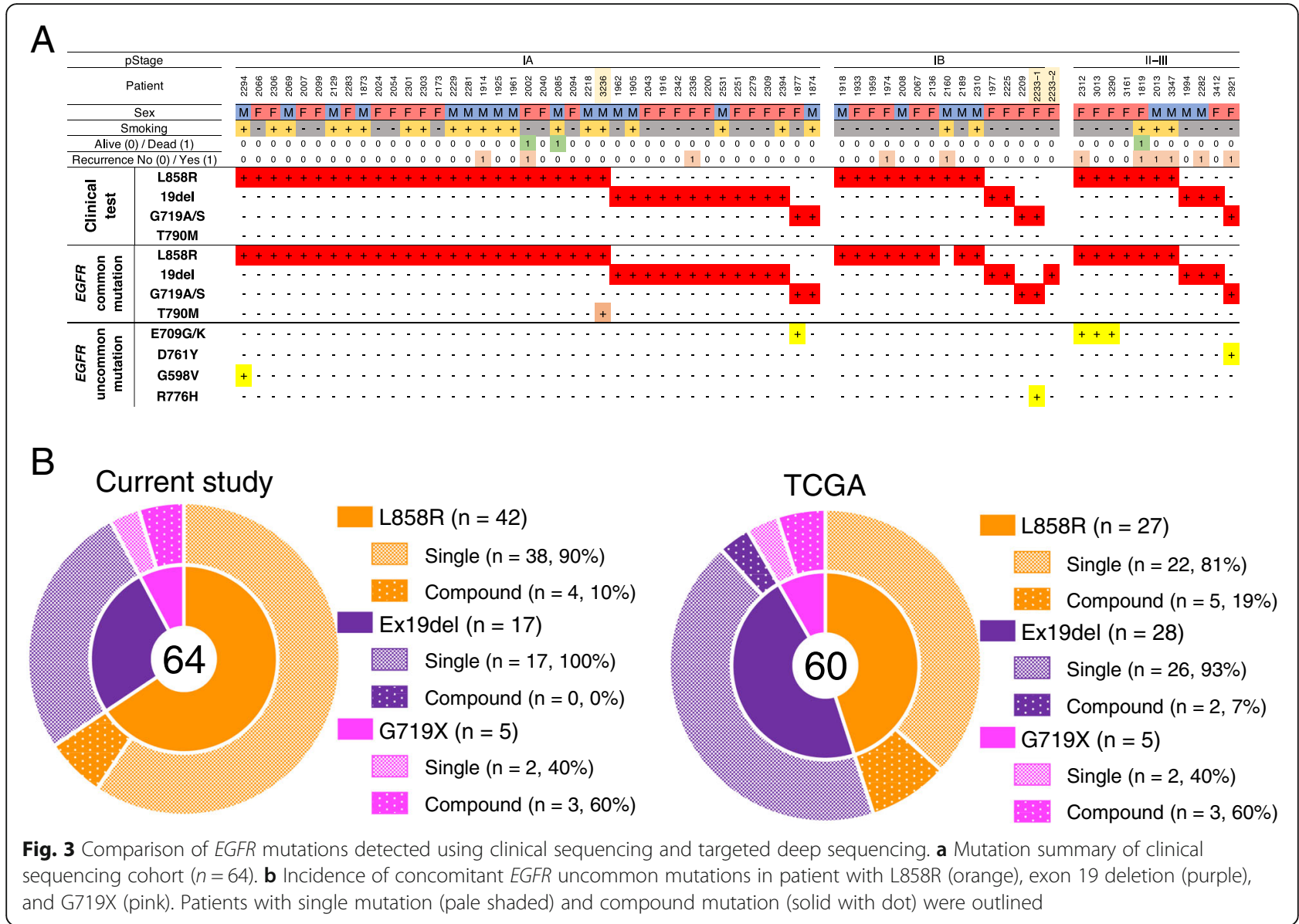

gene sets were negatively correlated, such as "reactive oxygen species pathway" and "pancreas beta cells" (Additional file 8: Figure S3C).

\section{Discussion}

In the current study, we demonstrated the feasibility of a molecular barcoding system to reduce potential sequence artifacts, especially during targeted deep sequencing. The correspondence rate between the common EGFR mutation profiles produced by MBS and clinical tests was $98.4 \%$ (63 out of 64 cases). The discordance was observed in only one patient \#2160, in whom L858R mutation was positive at clinical testing but negative at NGS. In clinical testing, gDNA was extracted from FFPE sample, whereas gDNA from fresh frozen sample was used for NGS. These differences of samples from the same patient, in other words tumor heterogeneity may be the cause of the discordance.

We identified a de novo T790 M mutation that could not be detected by clinical tests, representing a potential advantage of this system. We also used molecular barcoding to investigate the status of uncommon EGFR mutations coexisting with common mutations in treatment-naïve primary lung cancer patients. In the

Table 1 Allele frequency of common and uncommon EGFR mutations

\begin{tabular}{llllll}
\hline Patient & Common mutation & Frequency (\%) & Uncommon mutation & Frequency (\%) & Difference (\%) \\
\hline 2294 & L858R & 6.56 & G598 V & 6.8 & 0.24 \\
2312 & L858R & 13.3 & E709G & 13.9 & 0.6 \\
3013 & L858R & 20.4 & E709G & 20.4 & 0 \\
3290 & L858R & 20.2 & E709G & 18.4 & 1.8 \\
1877 & G719S & 11.8 & E709G & 12.3 & 0.5 \\
2233 & G719S & 30.9 & R776H & 48.1 & 17.2 \\
2921 & G719A & 19.4 & D761Y & 65.9 & 46.5 \\
\hline
\end{tabular}


Table 2 Clinical and pathologic characteristics of the cases with EGFR single/compound mutation

\begin{tabular}{|c|c|c|c|c|}
\hline Parameter & Subtype & Single $(n=57)$ & Compound $(n=7)$ & $P$-value \\
\hline${ }^{\mathrm{a}}$ Mean age $($ mean $\pm \mathrm{SD})$; yrs & & $66.4 \pm 9.6$ & $66.7 \pm 9.3$ & 0.94 \\
\hline \multirow[t]{2}{*}{${ }^{b}$ Sex, n (\%) } & Male & 23 & 1 & \multirow[t]{2}{*}{0.24} \\
\hline & Female & 34 & 6 & \\
\hline \multirow[t]{2}{*}{ 'SSmoking habit, n (\%) } & No & 31 & 6 & \multirow[t]{2}{*}{0.22} \\
\hline & Yes & 26 & 1 & \\
\hline \multirow[t]{3}{*}{ bEGFR mutation, $\mathrm{n}(\%)$} & L858R & 38 & 4 & \multirow[t]{3}{*}{$0.0052^{*}$} \\
\hline & Exon19del & 17 & 0 & \\
\hline & G719A/S & 2 & 3 & \\
\hline${ }^{\mathrm{a}}$ Tumor size (mean $\pm \mathrm{SD}$ ); mm & & $22.5 \pm 8.9$ & $33.7 \pm 23.3$ & $0.014^{*}$ \\
\hline \multirow[t]{3}{*}{ bpStage, n (\%) } & IA & 37 & 2 & \multirow[t]{3}{*}{$0.012^{*}$} \\
\hline & IB & 13 & 1 & \\
\hline & $\|A-\| B$ & 7 & 4 & \\
\hline
\end{tabular}

${ }^{a} P$-value was obtained from t-test

${ }^{\mathrm{b}} P$-value was obtained from Fisher's test

A value of $p<0.05$ was marked "*"

past decade, different frequencies of uncommon EGFR mutations found together with common mutations have been documented, ranging from 3.6 to $14.8 \%$ [14, 27-30]. Moreover, several NGS-based studies have reported an incidence of EGFR compound mutations of 3.0 to $16 \%$ in EGFR-mutated lung cancers $[25,31]$. In our study, uncommon EGFR mutations were detected in $10.9 \%(7 / 64)$ of cases.

We also showed that EGFR G719X-harboring cases had a significantly higher incidence of concomitant uncommon EGFR mutations than those with L858R or exon 19 deletion mutations. This result supported the findings of large-scale analyses of over 1000 cases reported by Illei et al. [25] and Wu et al. [30], suggesting that patients with the G719X mutation are likely to have EGFR compound mutations. In addition, Kohsaka et al. has reported that more than $90 \%$ of the G719 mutations existed as compound mutations while only 19.5 and $4.7 \%$ of L858R mutations and exon 19 deletions respectively harbor compound mutations [24].

Lung cancer patients harboring G719X mutations were reported to have lower sensitivities to first-generation EGFR-TKIs and shorter survival times than those with L858R mutations or an exon 19 deletion [32, 33]. Previously, we described the first known case of an individual with a combination of D761Y and L858R mutations who did not respond to gefitinib, which was confirmed by other groups [34, 35]. Some germline EGFR mutations, including T790 M, V843I, and R776H, have been considered to predispose subjects to familial lung cancer and exhibit clinical resistance to EGFR-TKI [36-39]. Altogether, it is clinically important to know the mutation profile of both uncommon and common EGFR mutations for patients with NSCLC.

\section{Conclusion}

Amplicon sequencing incorporating an MBS is a feasible approach to determine the mutation profile of both uncommon and common EGFR mutations. Uncovering the true genotype using an accurate NGS platform will enable the development of proper therapeutic strategies for NSCLC.

\section{Additional files}

Additional file 1: Figure S1. Patients population. Of 531 patients
without any treatment before surgery, 415 (78\%) were diagnosed as
having adenocarcinoma. Based on clinical tests, 169 patients were
diagnosed as EGFR-mutation positive. Of the 169 EGFR-mutation positive
adenocarcinomas, 64 adenocarcinoma specimens were randomly
selected and sequenced with MBS. (PDF 315 kb)
Additional file 2: Table S1. ClearSeq Cancer Panel Gene List. (XLSX 10 kb)
Additional file 3: Table S2. DNA sequencing primer. (XLSX 10 kb)
Additional file 4: Table S3. Patient characteristics. (XLSX 14 kb)
Additional file 5: Table S4. Reproducibility of targeted deep
sequencing without MBS. (XLSX 12 kb)
Additional file 6: Figure S2. EGFR uncommon mutations detected by
targeted sequencing. All the uncommon EGFR mutations detected in 7
cases were confirmed by direct sequencing. ECD, Extra-cellular Domain.
(PDF 1223 kb)
Additional file 7: Table S5. Patient characteristics. (XLSX 10 kb)
Additional file 8: Figure S3. Molecular profiles of EGFR compound
mutations. (A) In patients with the G719X compound mutation, five
genes were highly induced while six genes were significantly repressed.
In total, 11 genes were significantly altered in patient with the G719X
compound mutation, while only 3 genes were significantly repressed in
patient with the L858R compound mutation and 6 genes were altered in
patient with the Ex19del compound mutation. (B) All the five significantly
induced genes were unique for patient with the G719X compound
mutation, while three out of six significantly down-regulated genes were
overlapped with those of patient with the Ex19del compound mutation.
(C)We performed GSEA using hallmark gene sets, revealing that several
gene sets were correlated with the patient with the G719X compound
mutation. (PDF 168 kb)




\section{Abbreviations}

COSMIC: Catalogue of somatic mutations in cancer; EGFR: Epidermal growth factor receptor; MBS: Molecular barcoding system; NGS: Next-generation sequencing; NSCLC: Non-small cell lung cancer; PCR: Polymerase chain reaction; TCGA: The Cancer Genome Atlas; TKI: Tyrosine kinase inhibitor

\section{Acknowledgements}

The authors thank Ms. Fumiko Isobe (Department of Thoracic, Breast and Endocrinological Surgery, Okayama University Graduate School of Medicine, Dentistry and Pharmaceutical Sciences, Okayama, Japan), Ms. Yuko Hanafusa (Okayama University Hospital Biobank, Okayama University Hospital, Okayama, Japan) for their technical support, and Dr. Hugh Colvin for valuable comments to improve the manuscript.

\section{Funding}

This study was supported in part by the Grant-in-Aid for Scientific Research from Japan Society for the Promotion of Science (JSPS KAKENHI Grant Number: 16H05431, 16H01574 and 17K1078409), and Boehringer Ingelheim Japan $\mathrm{Co}$. The funding agencies were not involved in in the design of the study and collection, analysis, and interpretation of data and in writing the manuscript.

\section{Availability of data and materials}

Amplicon-based targeted sequencing data with the molecular barcoding system are available in the Sequence Read Archive (SRA) repository (PRJNA518750). All of the variants identified in this study including mutations supporting the conclusions in this article are included in Additional file 4: Table S3 for per-patient EGFR major mutations, Additional file 5: Table S4 for uncommon EGFR mutations as amino acid changes.

\section{Authors' contributions}

KN, ST1 and ST2 were project leaders. KN, ST1 and ST2 wrote the manuscript. $\mathrm{KN}, \mathrm{YT}, \mathrm{EK}, \mathrm{YO}, \mathrm{TY}, \mathrm{TT}, \mathrm{HT}, \mathrm{HS}, \mathrm{KS}, \mathrm{HY}, \mathrm{JS}$ and $\mathrm{KT}$ analyzed clinicopathological data. KN, ST1 and TM examined genomic alterations and performed bioinformatics analysis. KN, ST1, KS, HY, JS, KT and ST2 supervised the statistical analysis. All authors read and approved the final manuscript.

\section{Ethics approval and consent to participate}

This study complied with the standards of the Declaration of Helsinki and the current ethical guidelines, and was approved by the Institutional Review Board (Okayama University Graduate School of Medicine, Dentistry and Pharmaceutical Sciences and Okayama University Hospital, Ethical Committee) (permission number; K1609-042-001). A written informed consent was obtained from all patients before surgery.

\section{Consent for publication}

Not applicable.

\section{Competing interests}

SToyooka was funded by Boehringer Ingelheim Japan Co. The remaining authors declare that they have no competing interests.

\section{Publisher's Note}

Springer Nature remains neutral with regard to jurisdictional claims in published maps and institutional affiliations.

\section{Author details}

'Departments of Thoracic, Breast and Endocrinological Surgery, Okayama University Graduate School of Medicine, Dentistry and Pharmaceutical Sciences, 2-5-1 Shikata-cho, Kita-ku, Okayama City 700-8558, Japan. ${ }^{2}$ Department of Biobank, Okayama University Graduate School of Medicine, Dentistry and Pharmaceutical Sciences, 2-5-1 Shikata-cho, Kita-ku, Okayama City 700-8558, Japan. ${ }^{3}$ Okayama University Hospital Biobank, Okayama University Hospital, 2-5-1 Shikata-cho, Kita-ku, Okayama City 700-8558, Japan. ${ }^{4}$ Department of Gastroenterological Surgery, Okayama University Graduate School of Medicine, Dentistry and Pharmaceutical Sciences, 2-5-1 Shikata-cho, Kita-ku, Okayama City 700-8558, Japan. ${ }^{5}$ Department of Clinical Pharmacy, Okayama University Graduate School of Medicine, Dentistry and Pharmaceutical Sciences, 2-5-1 Shikata-cho, Kita-ku, Okayama City, Okayama 700-8558, Japan.
Received: 18 August 2018 Accepted: 18 February 2019

Published online: 26 February 2019

\section{References}

1. Torre LA, Bray F, Siegel RL, Ferlay J, Lortet-Tieulent J, Jemal A. Global cancer statistics, 2012. CA Cancer J Clin. 2015;65(2):87-108.

2. Siegel RL, Miller KD, Jemal A. Cancer statistics, 2015. CA Cancer J Clin. 2015; 65(1):5-29.

3. Rosell R, Moran T, Queralt C, Porta R, Cardenal F, Camps C, Majem M, LopezVivanco G, Isla D, Provencio M, et al. Screening for epidermal growth factor receptor mutations in lung cancer. N Engl J Med. 2009;361(10):958-67.

4. Shigematsu H, Lin L, Takahashi T, Nomura M, Suzuki M, Wistuba II, Fong KM, Lee H, Toyooka S, Shimizu N, et al. Clinical and biological features associated with epidermal growth factor receptor gene mutations in lung cancers. J Natl Cancer Inst. 2005;97(5):339-46.

5. Mok TS, Wu YL, Thongprasert S, Yang CH, Chu DT, Saijo N, Sunpaweravong $P$, Han B, Margono B, Ichinose $Y$, et al. Gefitinib or carboplatin-paclitaxel in pulmonary adenocarcinoma. N Engl J Med. 2009;361(10):947-57.

6. Wu JY, Yu CJ, Yang CH, Wu SG, Chiu YH, Gow CH, Chang YC, Hsu YC, Wei PF, Shih JY, et al. First- or second-line therapy with gefitinib produces equal survival in non-small cell lung cancer. Am J Respir Crit Care Med. 2008; 178(8):847-53.

7. Mitsudomi T, Kosaka T, Endoh H, Horio Y, Hida T, Mori S, Hatooka S, Shinoda M, Takahashi T, Yatabe Y. Mutations of the epidermal growth factor receptor gene predict prolonged survival after gefitinib treatment in patients with non-small-cell lung cancer with postoperative recurrence. J Clin Oncol. 2005;23(11):2513-20.

8. Campbell JD, Alexandrov A, Kim J, Wala J, Berger AH, Pedamallu CS, Shukla SA, Guo G, Brooks AN, Murray BA, et al. Distinct patterns of somatic genome alterations in lung adenocarcinomas and squamous cell carcinomas. Nat Genet. 2016;48(6):607-16.

9. Paez JG, Janne PA, Lee JC, Tracy S, Greulich H, Gabriel S, Herman P, Kaye FJ, Lindeman N, Boggon TJ, et al. EGFR mutations in lung cancer: correlation with clinical response to gefitinib therapy. Science. 2004;304(5676):1497-500.

10. Lynch TJ, Bell DW, Sordella R, Gurubhagavatula S, Okimoto RA, Brannigan BW, Harris PL, Haserlat SM, Supko JG, Haluska FG, et al. Activating mutations in the epidermal growth factor receptor underlying responsiveness of nonsmall-cell lung cancer to gefitinib. N Engl J Med. 2004;350(21):2129-39.

11. Pao W, Miller V, Zakowski M, Doherty J, Politi K, Sarkaria I, Singh B, Heelan R, Rusch V, Fulton L, et al. EGF receptor gene mutations are common in lung cancers from "never smokers" and are associated with sensitivity of tumors to gefitinib and erlotinib. Proc Natl Acad Sci U S A. 2004;101(36):13306-11.

12. Ercan D, Choi HG, Yun CH, Capelletti M, Xie T, Eck MJ, Gray NS, Janne PA. EGFR mutations and resistance to irreversible pyrimidine-based EGFR inhibitors. Clin Cancer Res. 2015;21(17):3913-23.

13. Kim EY, Cho EN, Park HS, Hong JY, Lim S, Youn JP, Hwang SY, Chang YS Compound EGFR mutation is frequently detected with co-mutations of actionable genes and associated with poor clinical outcome in lung adenocarcinoma. Cancer Biol Ther. 2016;17(3):237-45.

14. Kobayashi S, Canepa HM, Bailey AS, Nakayama S, Yamaguchi N, Goldstein MA, Huberman MS, Costa DB. Compound EGFR mutations and response to EGFR tyrosine kinase inhibitors. J Thorac Oncol. 2013;8(1):45-51.

15. Murray S, Dahabreh IJ, Linardou H, Manoloukos M, Bafaloukos D, Kosmidis P. Somatic mutations of the tyrosine kinase domain of epidermal growth factor receptor and tyrosine kinase inhibitor response to TKls in non-small cell lung cancer: an analytical database. J Thorac Oncol. 2008;3(8):832-9.

16. Metzker ML. Sequencing technologies - the next generation. Nat Rev Genet. 2010;11(1):31-46.

17. Meacham F, Boffelli D, Dhahbi J, Martin Dl, Singer M, Pachter L. Identification and correction of systematic error in high-throughput sequence data. BMC Bioinformatics. 2011;12:451.

18. Peng Q, Vijaya Satya R, Lewis M, Randad P, Wang Y. Reducing amplification artifacts in high multiplex amplicon sequencing by using molecular barcodes. BMC Genomics. 2015;16:589.

19. Kennedy SR, Schmitt MW, Fox EJ, Kohrn BF, Salk JJ, Ahn EH, Prindle MJ, Kuong KJ, Shen JC, Risques RA, et al. Detecting ultralow-frequency mutations by duplex sequencing. Nat Protoc. 2014;9(11):2586-606.

20. Schmitt MW, Kennedy SR, Salk JJ, Fox EJ, Hiatt JB, Loeb LA. Detection of ultra-rare mutations by next-generation sequencing. Proc Natl Acad Sci U S A. 2012;109(36):14508-13. 
21. Nagai $Y$, Miyazawa H, Huqun $\Pi$, Udagawa K, Kato M, Fukuyama S, Yokote A, Kobayashi K, Kanazawa M, et al. Genetic heterogeneity of the epidermal growth factor receptor in non-small cell lung cancer cell lines revealed by a rapid and sensitive detection system, the peptide nucleic acid-locked nucleic acid PCR clamp. Cancer Res. 2005;65(16): 7276-82.

22. Subramanian A, Tamayo P, Mootha VK, Mukherjee S, Ebert BL, Gillette MA, Paulovich A, Pomeroy SL, Golub TR, Lander ES, et al. Gene set enrichment analysis: a knowledge-based approach for interpreting genome-wide expression profiles. Proc Natl Acad Sci U S A. 2005; 102(43):15545-50.

23. Lee JC, Vivanco I, Beroukhim R, Huang JH, Feng WL, DeBiasi RM, Yoshimoto K, King JC, Nghiemphu P, Yuza Y, et al. Epidermal growth factor receptor activation in glioblastoma through novel missense mutations in the extracellular domain. PLoS Med. 2006;3(12):e485.

24. Kohsaka S, Nagano M, Ueno T, Suehara Y, Hayashi T, Shimada N, Takahashi K, Suzuki K, Takamochi K, Takahashi F, et al. A method of high-throughput functional evaluation of EGFR gene variants of unknown significance in cancer. Sci Transl Med. 2017:9(416):eaan6566.

25. Illei PB, Belchis D, Tseng LH, Nguyen D, De Marchi F, Haley L, Riel S, Beierl K, Zheng G, Brahmer JR, et al. Clinical mutational profiling of 1006 lung cancers by next generation sequencing. Oncotarget. 2017; 8(57):96684.

26. Wu JY, Shih JY. Effectiveness of tyrosine kinase inhibitors on uncommon E709X epidermal growth factor receptor mutations in non-small-cell lung cancer. Onco Targets Ther. 2016;9:6137-45.

27. Mitsudomi T, Yatabe Y. Mutations of the epidermal growth factor receptor gene and related genes as determinants of epidermal growth factor receptor tyrosine kinase inhibitors sensitivity in lung cancer. Cancer Sci. 2007;98(12):1817-24

28. Peng $L$, Song $Z$, Jiao S. Comparison of uncommon EGFR exon 21 L858R compound mutations with single mutation. Onco Targets Ther. 2015;8:905-10.

29. Wu SG, Chang YL, Hsu YC, Wu JY, Yang CH, Yu CJ, Tsai MF, Shih JY, Yang PC. Good response to gefitinib in lung adenocarcinoma of complex epidermal growth factor receptor (EGFR) mutations with the classical mutation pattern. Oncologist. 2008;13(12):1276-84.

30. Wu JY, Yu CJ, Chang YC, Yang CH, Shih JY, Yang PC. Effectiveness of tyrosine kinase inhibitors on "uncommon" epidermal growth factor receptor mutations of unknown clinical significance in non-small cell lung cancer. Clin Cancer Res. 2011;17(11):3812-21.

31. Li S, Li L, Zhu Y, Huang C, Qin Y, Liu H, Ren-Heidenreich L, Shi B, Ren H, Chu $X$, et al. Coexistence of EGFR with KRAS, or BRAF, or PIK3CA somatic mutations in lung cancer: a comprehensive mutation profiling from 5125 Chinese cohorts. Br J Cancer. 2014;110(11):2812-20.

32. Kobayashi $Y$, Togashi $Y$, Yatabe $Y$, Mizuuchi H, Jangchul P, Kondo C, Shimoji M, Sato K, Suda K, Tomizawa K, et al. EGFR exon 18 mutations in lung cancer: molecular predictors of augmented sensitivity to Afatinib or Neratinib as compared with first- or third-generation TKls. Clin Cancer Res. 2015;21(23):5305-13.

33. Watanabe $S$, Minegishi $Y$, Yoshizawa $H$, Maemondo $M$, Inoue A, Sugawara S, Isobe $H$, Harada M, Ishii Y, Gemma A, et al. Effectiveness of gefitinib against non-small-cell lung cancer with the uncommon EGFR mutations G719X and L861Q. J Thorac Oncol. 2014;9(2):189-94.

34. Pao W, Miller VA, Politi KA, Riely GJ, Somwar R, Zakowski MF, Kris MG, Varmus $\mathrm{H}$. Acquired resistance of lung adenocarcinomas to gefitinib or erlotinib is associated with a second mutation in the EGFR kinase domain. PLoS Med. 2005;2(3):e73.

35. Tokumo M, Toyooka S, Ichihara S, Ohashi K, Tsukuda K, Ichimura K, Tabata M, Kiura K, Aoe M, Sano Y, et al. Double mutation and gene copy number of EGFR in gefitinib refractory non-small-cell lung cancer. Lung Cancer. 2006:53(1):117-21.

36. Ohtsuka K, Ohnishi H, Kurai D, Matsushima S, Morishita Y, Shinonaga M, Goto H, Watanabe T. Familial lung adenocarcinoma caused by the EGFR V843l germ-line mutation. J Clin Oncol. 2011;29(8):e191-2.

37. van Noesel J, van der Ven WH, van Os TA, Kunst PW, Weegenaar J, Reinten RJ, Kancha RK, Duyster J, van Noesel CJ. Activating germline $\mathrm{R} 776 \mathrm{H}$ mutation in the epidermal growth factor receptor associated with lung cancer with squamous differentiation. J Clin Oncol. 2013; 31(10):e161-4.
38. Gazdar A, Robinson L, Oliver D, Xing C, Travis WD, Soh J, Toyooka S, Watumull L, Xie Y, Kernstine $K$, et al. Hereditary lung cancer syndrome targets never smokers with germline EGFR gene T790M mutations. J Thorac Oncol. 2014;9(4):456-63.

39. Bell DW, Gore I, Okimoto RA, Godin-Heymann N, Sordella R, Mulloy R, Sharma SV, Brannigan BW, Mohapatra G, Settleman J, et al. Inherited susceptibility to lung cancer may be associated with the T790M drug resistance mutation in EGFR. Nat Genet. 2005;37(12):1315-6.

\section{Ready to submit your research? Choose BMC and benefit from:}

- fast, convenient online submission

- thorough peer review by experienced researchers in your field

- rapid publication on acceptance

- support for research data, including large and complex data types

- gold Open Access which fosters wider collaboration and increased citations

- maximum visibility for your research: over $100 \mathrm{M}$ website views per year

At BMC, research is always in progress.

Learn more biomedcentral.com/submissions 